\title{
Obesity determinants among Malaysian schoolchildren: What is new?
}

\author{
A. Aryati ${ }^{1}$, N. Zulaily ${ }^{1}$, M.R. Shahril ${ }^{1}$, N.S. Abdul Manan ${ }^{2}$, S.A. Fadzli ${ }^{2}$, S.W. Wafa ${ }^{1}$, \\ R.M. Amin ${ }^{3}$ and A. Ahmed \\ ${ }^{1}$ Faculty of Health Sciences, Universiti Sultan Zainal Abidin, Terengganu, Malaysia, \\ ${ }^{2}$ Faculty of Informatics \& Computing, Universiti Sultan Zainal Abidin, Terengganu, Malaysia, \\ ${ }^{3}$ Faculty of Medicine, Universiti Sultan Zainal Abidin, Terengganu, Malaysia and \\ ${ }^{4}$ Institute of Engineering Mathematic, Universiti Malaysia Perlis, Malaysia
}

Obesity among schoolchildren has been regarded as one of the most serious public health challenges in this decade. This problem has now become more evident in the developing countries including Malaysia. It is linked with numerous risk factors mainly unhealthy lifestyle ${ }^{(1)}$. Despite many surveys that have been conducted globally, the latest data on its determinants among Malaysian schoolchildren, particularly in sub-urban state like Terengganu, is limited. Therefore, this study aimed to provide the current analysis on obesity determinants including demographic, socioeconomic status, dietary intake, physical activity, and physical fitness level and its relationship with childhood obesity. Using a cross-sectional study design, a total of 1,404 schoolchildren were involved in the study ( $46 \cdot 3 \%$ boys and $53.7 \%$ girls; $67.7 \%$ urban and $32.3 \%$ rural). Data on demographic and socioeconomic were gathered using a selfadministered questionnaire. Height and body weight were measured and BMI-for-age Z-score was calculated using WHO AnthroPlus software and compared with WHO BMI-for-age Z-score classifications (2007) ${ }^{(2)}$. Dietary intake and physical activity level were measured using FFQ and c-PAQ, respectively, whereas physical fitness level was assessed using SEGAK test, a standardised fitness norm test for Malaysian students. All data were analysed using multivariable analysis.

Interestingly in the final model, obesity in both genders was found to be positively associated with parental obesity, birth weight and serving of milk and dairy products intake whilst negatively associated with household size. Schoolchildren of father or mother with one unit higher in BMI, will have 0.073 unit or 0.069 unit higher in BMI Z-score, respectively $(\mathrm{P}<0.001)$. Schoolchildren who were $1 \mathrm{~kg}$ heavier at birth will have 0.357 unit higher in BMI Z-score $(\mathrm{P}=0.003)$. Similarly, an increase in one serving size of milk and dairy products intake will increase BMI Z-score by 0.194 unit $(\mathrm{P}=0.036)$. Nevertheless, schoolchildren with one extra household family member will have 0.085 unit lower in BMI Z-score $(\mathrm{P}=0.022)$. Overall, $13.1 \%$ of the variation in BMI Z-score was explained by father's BMI, mother's BMI, birth weight, household number, and serving size milk and dairy products according to the multiple linear regression $(\mathrm{MLR})$ model $\left(\mathrm{R}^{2}=0 \cdot 131\right)$.

\begin{tabular}{lccr}
\hline Variables & Regression Coefficient $(\beta)^{\mathrm{a}}$ & $95 \%$ CI & P-value \\
\hline BMI father & 0.073 & $0.044,0 \cdot 102$ & $<0.001$ \\
BMI mother & 0.069 & $0.038,0 \cdot 1$ & $<0.001$ \\
Birth weight & 0.357 & $0.123,0.59$ & 0.003 \\
Household number & -0.085 & $-0.158,-0.012$ & 0.022 \\
Serving size milk and dairy products & $0 \cdot 194$ & $0.013,0.375$ & 0.036 \\
\hline a Adjusted regression coefficient; Forward MLR applied. Coefficient of determination $\left(\mathrm{R}^{2}\right)=$ \\
0.131
\end{tabular}

This new finding suggests the requirement of multifaceted and community-wide programs and policies including parental important roles in obesity preventive strategies and interventions. Therapeutic lifestyle changes specifically in eating behaviour, through parental ingenuity and social support, remain the most important approaches in managing childhood obesity.

This study was funded by the Malaysian Ministry of Higher Education.

1. Gupta N, Goel K, Shah P \& Misra A (2012) Endocr Rev 3(1): 48-70

2. World Health Organization (2007) WHO Child Growth Standards [cited 2017 Mac 19] Available from: http://www.who.int/growthref/en/ 